\title{
Studies of $\boldsymbol{N}$-Acyl-2-pyridinecarboxanilides. Preparation by
} Various Reaction Sequences and Reaction with Hydrogen Chloride to give Acyl Imidate Hydrochlorides through an Intramolecular $N \rightarrow O$ Acyl Migration

\author{
EVA H. MØRKVED
}

Organic Chemistry Laboratories, Norwegian Institute of Technology, University of Trondheim, N-7034 Trondheim-NTH, Norway

The preparation of $N$-acyl-2-pyridinecarboxanilides from imidoyl chlorides and salts of carboxylic acids is reported. Only small amounts of the same $N$ acylamides are obtained from acylations of 2pyridinecarboxanilides with acyl chlorides and a base. Treatment of the $N$-acyl-2-pyridinecarboxanilides with hydrogen chloride induces an intramolecular $N \rightarrow O$ acyl migration and the corresponding acyl imidate hydrochlorides are obtained.

In order to improve our understanding of various intramolecular acyl-transfer reactions of $\mathrm{N}$-acyl-4dialkylamino-2-pyridinecarboxanilides the $\mathrm{N}$ acylamides 3 have been chosen as reference compounds. These $N$-acylamides are easily prepared by reactions of imidoyl chlorides with carboxylate ions, i.e. by methods (A) and (B), in Scheme 1. Attempts to prepare 3 by direct acylation of amides either result in low yields of 3 or fail completely.

An interesting intramolecular $N \rightarrow O$ acyl migration is observed upon treating 3 with hydrogen chloride, the products being the acyl imidate hydrochlorides 4; cf. Scheme 1.

Reactions of the 2-pyridinecarboxanilides 1 with acyl chlorides in the absence of an external base were expected ${ }^{1}$ to yield 4 but only the hydrochlorides of 1 are obtained from such reactions.

\section{RESULTS}

The $N$-acyl-2-pyridinecarboxanilides $3 a-o$ are prepared either by reactions of carboxylate ions with the 2-pyridinecarboximidoyl chloride hydrochlorides 2 and triethylamine, method (A), or by reactions of triethylammonium 2-pyridinecarboxylate with imidoyl chlorides, method (B), in Scheme 1 and Table 1 . Several of the $N$-acylamides 3 were prepared by both methods thus confirming the structure of these compounds; for each set of $\mathbf{R}^{\prime}$ and $\mathbf{R}^{\prime \prime}$ substituents two different acyl imidates would initially be formed, one by method (A) and another by (B). These compounds subsequently rearrange through the expected ${ }^{2} O \rightarrow N$ acyl migrations to give the same $\mathrm{N}$-acylamide 3 .

Reactions of the 2-pyridinecarboxanilides 1 with acyl chlorides and an external base, method (C), were expected to yield 3 , particularly since the somewhat related isoquinoline-1-carboxanilide easily was benzoylated in a pyridine solution. ${ }^{3}$ However, various attempts to acylate 1 were generally unsuccessful; for instance, low yields of $3 b$ were obtained from reactions of $1 a$ with benzoyl chloride in the presence of either triethylamine or sodium hydride. Extensive decomposition of the pyridine ring was apparent ${ }^{4}$ during reactions in polar solvents of $1 d$ with acyl chlorides and various bases, or of 2-pyridinecarbonyl chloride with acetanilide and triethylamine.

Reactions of $1 b$ with one molar equivalent of sodium hydride in tetrahydrofuran and with a molar excess of either acetyl chloride or benzoyl chloride gave low yields of two products which showed the presence of halide. These compounds had IR spectra similar to those of the acyl imidate 
A.
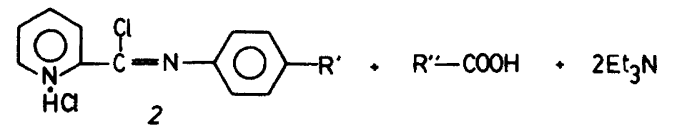

B.

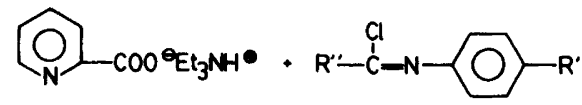

c.
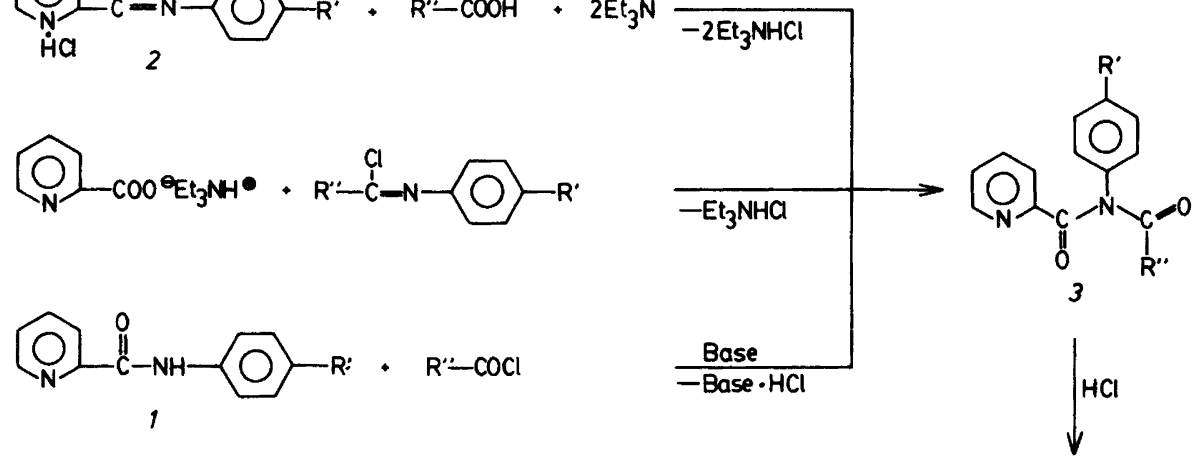

\begin{tabular}{l|l}
1.2 & $\mathrm{R}^{\prime}$ \\
\hline a & $\mathrm{Me}$ \\
b & $\mathrm{H}$ \\
c & $\mathrm{MeO}$ \\
d & $\mathrm{Cl}$ \\
e & $\mathrm{NO}_{2}$
\end{tabular}

\begin{tabular}{|c|c|c|}
\hline 3.4 & $\mathrm{R}^{\prime}$ & $\mathrm{R}^{\prime \prime}$ \\
\hline$a-c$ & $\mathrm{Me}$ & \\
\hline$d-f$ & $H$ & \\
\hline $9-i$ & $\mathrm{MeO}$ & $\mathrm{Me}: \mathrm{Ph} ; 4-\mathrm{Ph}-\mathrm{Pr}$ \\
\hline$j-1$ & $\mathrm{Cl}$ & \\
\hline$m-0$ & $\mathrm{NO}$, & \\
\hline
\end{tabular}

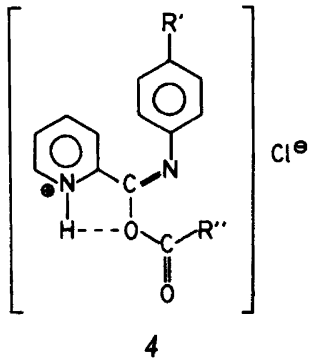

Scheme 1.

Table 1. $N$-Acyl-2-pyridinecarboxanilides.

\begin{tabular}{|c|c|c|c|c|c|c|c|}
\hline \multirow{3}{*}{$\begin{array}{l}\text { Com- } \\
\text { pound }\end{array}$} & \multirow{2}{*}{\multicolumn{2}{|c|}{$\begin{array}{l}\text { Yield/\% } \\
\text { Method }\end{array}$}} & \multirow{3}{*}{ M.p. $/{ }^{\circ} \mathrm{C}$} & \multicolumn{2}{|l|}{ Mol.wt. } & \multirow{3}{*}{$\begin{array}{l}\mathrm{IR} / \mathrm{cm}^{-1 a} \\
\mathrm{HCB}^{b}\end{array}$} & \multirow{2}{*}{$\begin{array}{l}{ }^{1} \mathrm{H} \mathrm{NMR} / \delta \\
\mathrm{CDCl}_{3}\end{array}$} \\
\hline & & & & Ohs & Cols & & \\
\hline & $\mathbf{A}$ & B & & Oos. & Caic. & & \\
\hline $3 a$ & 67 & & $97-98$ & 254.1057 & 254.1055 & $1370(s)$ & 2.26 \\
\hline $3 b$ & 70 & & $122-123$ & 316.1213 & 316.1212 & & \\
\hline $3 c$ & 68 & & $129-131$ & 392.1521 & 392.1525 & & \\
\hline $3 d$ & 66 & & $75-77$ & 240.0899 & 240.0899 & $1370(s)$ & 2.26 \\
\hline $3 e^{c}$ & 83 & 97 & $125-126$ & 302.1053 & 302.1055 & & \\
\hline $3 f$ & 54 & 45 & $123-125$ & 378.1366 & 378.1368 & & \\
\hline $3 g$ & 67 & & $84-86$ & 270.1000 & 270.1004 & $1370(\mathrm{~s})$ & 2.24 \\
\hline $3 h$ & 80 & & $145-146$ & 332.1161 & 332.1161 & & \\
\hline $3 i$ & 64 & & $132-134$ & 408.1474 & 408.1474 & & $\cdot$ \\
\hline $3 j$ & 36 & 29 & $89-91$ & 274.0511 & 274.0509 & 1372 (s) & 2.31 \\
\hline $3 k$ & 66 & 89 & $125-126$ & 336.0663 & 336.0665 & & \\
\hline $3 l$ & 48 & & $110-112$ & 412.0983 & 412.0979 & & \\
\hline $3 m$ & 45 & & $137-139$ & 285.0752 & 285.0750 & $d$ & 2.46 \\
\hline $3 n$ & 61 & 85 & $160-161$ & 347.0901 & 347.0906 & & \\
\hline $3 o$ & & 76 & $150-151$ & 423.1222 & 423.1219 & & \\
\hline
\end{tabular}

${ }^{a}$ IR (nujol): Compounds 3 show two carbonyl absorptions in the region $1710-1660 \mathrm{~cm}^{-1}$. ${ }^{b}$ Hexachlorobutadiene. ' Previously reported, $c f$. Ref. $3 .{ }^{d}$ Nitro groups absorb in this region.

Acta Chem. Scand. B $34(1980)$ No. 5 
Table 2. Acyl imidate hydrochlorides.

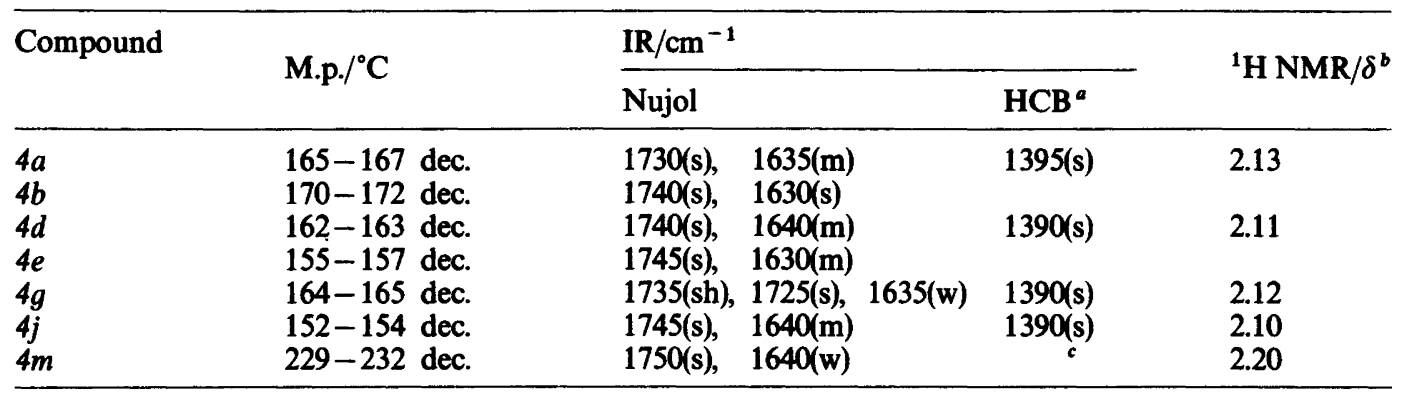
a Hexachlorobutadiene. ${ }^{b}$ In a mixture of deuteriochloroform and methanol- $d_{4}$ except $4 j$ which was dissolved in
deuteriochloroform and acetonitrile- $d_{3}$. ${ }^{c}$ Nitro groups absorb in this region.

hydrochlorides which previously had been obtained $^{1}$ from 4-(1-pyrrolidinyl)-2-pyridinecarboxanilides and acyl chlorides. The structures $4 d$ and $4 e$ were tentatively assigned to these compounds in agreement with the observed molecular weights. Attempts to acylate the amides 1 with either benzoyl chloride or acetyl chloride only yielded the hydrochlorides of 1 . However, when the $N$-acylamides $3 d$ and $3 e$ were treated with hydrogen chloride the products which were obtained were identical to $4 d$ and $4 e$, respectively. The implication of these results is that upon treatment of 3 with hydrogen chloride, an intramolecular $N \rightarrow O$ acyl migration occurs. Even if $N, N$-diacylamines usually are more stable than acyl imidates, i.e. $N$-acyl groups are more stable than $\boldsymbol{O}$-acyl groups, examples are known to the contrary. For instance, 2-acetoxypyridine is found to be far more stable than $N$-acetyl-2(1H)pyridone. ${ }^{5}$ The possibility of a conversion of $N$ acylamides to acyl imidates also has been considered for $\boldsymbol{N}$-formylamides. ${ }^{6}$

The $N$-acylamides $3 a, 3 d, 3 g, 3 j$ and $3 m$ which have an $\mathrm{N}$-acetyl group were treated with hydrogen chloride and ${ }^{1} \mathrm{H}$ NMR and IR absorptions of the products are shown in Table 2. A comparison of the IR absorptions of 3, Table 1, with those of the above products shows a marked shift of the double carbonyl absorption at $1710-1660 \mathrm{~cm}^{-1}$ for 3 to one strong absorption at $1750-1730 \mathrm{~cm}^{-1}$ for the hydrogen chloride treated $\mathrm{N}$-acylamides. This shift towards higher frequencies in addition to the appearance of a new absorption at 1640-1635 $\mathrm{cm}^{-1}$, the latter being interpreted as a $\mathrm{C}=\mathrm{N}$ absorption, is in accord with an acyl imidate structure. ${ }^{5 a, 7}$ It may be noted that a similar change in the carbonyl absorption is not observed upon treating the 2-pyridinecarboxanilides 1 with hydrogen chloride. IR spectra of 3 and the hydrogen chloride treated $\mathrm{N}$-acylamides also were recorded using the mulling agent hexachlorobutadiene which is transparent in the $1400-1300 \mathrm{~cm}^{-1}$ region. The absorption of 3 at $1370 \mathrm{~cm}^{-1}$ is shifted to $1390 \mathrm{~cm}^{-1}$ after treatment with hydrogen chloride and this shift is interpreted as a change from an acetyl group to an acetoxy group. ${ }^{8}$

The ${ }^{1} \mathrm{H}$ NMR signals of the acetyl protons of these $N$-acylamides are shifted towards lower $\delta$ values upon treatment with hydrogen chloride and this increase in shielding of the methyl protons is in the right direction for a change from the acetyl group of 3 to the acetoxy group of 4 . The changes in $\delta$-values are small, $\Delta \delta 0.12-0.26$, and it might be argued that these changes are insignificant. However, these observations are in good agreement with $\Delta \delta 0.28$ which was found ${ }^{9}$ for some pyrrole derivatives; the methyl protons of an $\mathrm{N}$ acetyl group were recorded at $\delta 2.40$ and those of a corresponding acetoxy group at $\delta$ 2.12. Also, it may be argued that the hydrochlorides of 3 are expected to show methyl absorptions at higher $\delta$ than the $N$-acetylamides. Thus, the conformation of 3 which is shown in Scheme 1 apparently is the preferred one ${ }^{6}$ and a protonation of the pyridinenitrogen would have a deshielding effect on the methyl protons of the acetyl group of 3 .

In addition to the $N$-acylamides 3 with $R^{\prime \prime}=M e$, $3 b$ with $\mathbf{R}^{\prime \prime}=\mathrm{Ph}$ was treated with hydrogen chloride. This product also shows an IR carbonyl absorption at a higher frequency than the $N$-acylamide $3 b$, see Tables 1 and 2.

In conclusion, the various data presented above point in the same direction and are interpreted as 
convincing evidence for an intramolecular $N \rightarrow O$ acyl migration, i.e. the acyl imidates 4 are formed upon treatment of 3 with hydrogen chloride. Further analyses of these and related compounds by ${ }^{13} \mathrm{C}$ NMR have been initiated.*

\section{EXPERIMENTAL}

General. The instrumentation, the solvents and reagents have been described. ${ }^{1,3,10}$ Sodium hydride $55-60 \%$ in oil, practical grade, $N$-(4-chlorophenyl)acetamide, reagent grade, and Florisil, 60-100 mesh, were obtained from Fluka.

2-Pyridinecarboxanilides, 1. These are known compounds and the preparation of $1 a, 1 b$ and $1 e$ has been described. ${ }^{10}$ The same method was used to prepare $1 c$, m.p. $92-94{ }^{\circ} \mathrm{C}$, IR (nujol): 3360 (m), 1685 (s) cm ${ }^{-1}$, lit. ${ }^{11}$ m.p. $93-94{ }^{\circ} \mathrm{C}$ and $1 d$, m.p. $135-137^{\circ} \mathrm{C}$, IR (nujol): $3330(\mathrm{~m}), 1685(\mathrm{~s}) \mathrm{cm}^{-1}$, lit. ${ }^{11}$ m.p. $138-139^{\circ} \mathrm{C}$.

2-Pyridinecarboxanilide hydrochlorides, $1 \cdot \mathrm{HCl}$. Dry hydrogen chloride gas was led into a benzene solution of the 2-pyridinecarboxanilide. The precipitate was filtered off, washed with benzene and dried over phosphorus(V) oxide. $1 a \cdot \mathrm{HCl}$, m.p. $195-196{ }^{\circ} \mathrm{C}$, IR (nujol): $1685(\mathrm{~s}) \mathrm{cm}^{-1} \cdot 1 b \cdot \mathrm{HCl}$, m.p. $178-180^{\circ} \mathrm{C}$, IR (nujol): $1680(\mathrm{~s}) \mathrm{cm}^{-1} .1 c \cdot \mathrm{HCl}$, m.p. $190-193{ }^{\circ} \mathrm{C}$ dec. IR (nujol): 1670 (s) $\mathrm{cm}^{-1}$. $1 d \cdot \mathrm{HCl}$, m.p. $205-208{ }^{\circ} \mathrm{C}$ dec. IR (nujol): 1675 (s) $\mathrm{cm}^{-1} .1 e \cdot \mathrm{HCl}$, m.p. $234-236{ }^{\circ} \mathrm{C}$; this compound reverts to $1 e$ upon melting and also upon attempted recrystallization from nitromethane. IR (nujol): 1680 (s) $\mathrm{cm}^{-1}$.

2-Pyridinecarboximidoyl chloride hydrochlorides, 2. The preparation of $2 a, 2 b$ and $2 e$ has been described. ${ }^{10}$ Compound $2 c$ was obtained in $74 \%$ yield from $1 c$ and phosphorus(V) chloride in thionyl chloride, m.p. $133-135{ }^{\circ} \mathrm{C}$ dec. IR (nujol): 1650 (m) $\mathrm{cm}^{-1}$. MS $[\mathrm{m} / \mathrm{e}(\%$ rel.int. $)]: 246(0.4, \mathrm{M}-\mathrm{HCl})$. Mol.wt., 246.0562, calc. for $\mathrm{C}_{13} \mathrm{H}_{11} \mathrm{ClN}_{2} \mathrm{O}: 246.0559$. Compound $2 d$ was obtained in $93 \%$ yield by the same method, m.p. $167-170{ }^{\circ} \mathrm{C}$ dec. IR (nujol): $1660(\mathrm{~s}) \mathrm{cm}^{-1}$. MS $[\mathrm{m} / \mathrm{e}$ (\% rel.int.)]: $250(9.9$, $\mathrm{M}-\mathrm{HCl}$ ). Mol.wt. 250.0069, calc. for $\mathrm{C}_{12} \mathrm{H}_{8} \mathrm{Cl}_{2} \mathrm{~N}_{2}$ : 250.0064 .

Diarylamides. 4-Phenylbenzanilide was prepared from 4-biphenylcarbonyl chloride and aniline, m.p. $228-231{ }^{\circ} \mathrm{C}$. IR (nujol): 3330 (m), 1650 (s) $\mathrm{cm}^{-1}$. 4'-Nitro-4-phenylbenzanilide was prepared from 4-biphenylcarbonyl chloride and 4-nitroaniline, m.p. $263-265^{\circ} \mathrm{C} \mathrm{dec}$. IR (nujol): 3370 (m), 1665 (s) $\mathrm{cm}^{-1}$.

\footnotetext{
* An alternative conformation of 4 with a hydrogen bond between the pyridine $N-H$ and the imidate $N$ has been considered and cannot be ruled out presently. Work in progress is expected to resolve this problem.
}

Diarylimidoyl chlorides. These compounds were prepared from benzene solutions of the corresponding amides and phosphorus(V) chloride. $\mathrm{N}$ (4-Chlorophenyl)benzimidoyl chloride m.p. $61-$ $63{ }^{\circ} \mathrm{C}$, lit. ${ }^{12}$ m.p. $62{ }^{\circ} \mathrm{C}$. $\quad N$-(4-Nitrophenyl)benzimidoyl chloride, m.p. $116-118{ }^{\circ} \mathrm{C}$, lit. ${ }^{13} \mathrm{~m} . \mathrm{p}$. $114-116{ }^{\circ} \mathrm{C}$. $N$-Phenyl-4-phenylbenzimidoyl chloride, m.p. $117-118{ }^{\circ} \mathrm{C}$. IR (nujol): 1650 (s) $\mathrm{cm}^{-1}$. MS [m/e (\% rel.int.)]: 291 (14.2, M), 256 (100, $\mathrm{M}-\mathrm{Cl}$ ). Mol.wt., obs. 291.0809, calc. for $\mathrm{C}_{19} \mathrm{H}_{14} \mathrm{CIN}$ 291.0814. $\quad N$-(4-Nitrophenyl)-4-phenylbenzimidoyl chloride, m.p. $190-191{ }^{\circ} \mathrm{C}$, IR (nujol): 1660 (s) $\mathrm{cm}^{-1}$. MS [m/e (\% rel. int.)]: $336(11.6, \mathrm{M}), 301$ $(100, \mathrm{M}-\mathrm{Cl})$. Mol.wt., obs. 336.0667, calc. for $\mathrm{C}_{19} \mathrm{H}_{13} \mathrm{ClN}_{2} \mathrm{O}_{2} 336.0665$.

$N$-(4-Chlorophenyl)acetimidoyl chloride was prepared from the corresponding amide and phosphorus(V) chloride and was obtained as a yellow oil which was used immediately. IR (film): 1700 (s) $\mathrm{cm}^{-1}$.

N-Acyl-2-pyridinecarboxanilides, 3. Method $A$. To a suspension of 2 in acetonitrile was added either sodium acetate $(1 \mathrm{~mol} \mathrm{eq}$.) and triethylamine $(1 \mathrm{~mol}$ eq.), or benzoic acid ( 1 mol eq.) and triethylamine ( 2 mol eq.), or 4-biphenylcarboxylic acid (1 mol eq.) and triethylamine ( $2 \mathrm{~mol}$ eq.). The reaction mixture was stirred at ambient temperature for $20-30 \mathrm{~h}$. The solvent was removed under reduced pressure and the solid residue was extracted with benzene. The benzene extract was chromatographed on silica gel with chloroform as eluent.

Method $B$. To an acetonitrile solution of equimolar amounts of picolinic acid and triethylamine was added the diaryl- or alkyl-arylimidoyl chloride (1 mol eq.). The reaction mixture was treated as described for method $\mathbf{A}$.

Acyl imidate hydrochlorides, 4 . The imide 3 was dissolved in benzene and dry hydrogen chloride gas was led through the solution. The yellow, oily precipitate which formed, crystallized upon addition of a small amount of acetone. Compound 4 was filtered and washed with diethyl ether.

Reaction of 1a with acylating agents and a base. A benzene solution of $1 a(212 \mathrm{mg}, 1 \mathrm{mmol})$, triethylamine $(110 \mathrm{mg}, 1.1 \mathrm{mmol})$ and benzoyl chloride $(140 \mathrm{mg}, 1 \mathrm{mmol})$ was heated at $80^{\circ} \mathrm{C}$ for $144 \mathrm{~h}$. The reaction mixture was filtered and chromatography on silica gel of the filtrate yielded $90 \mathrm{mg}(42 \%)$ of $1 a$, m.p. $100-102{ }^{\circ} \mathrm{C}$ and $55 \mathrm{mg}(17 \%)$ of $3 b$, m.p. $122-123^{\circ} \mathrm{C}$.

To a solution of $1 a(212 \mathrm{mg}, 1 \mathrm{mmol})$ in acetonitrile was added sodium hydride $(70 \mathrm{mg}, 1.5 \mathrm{mmol})$. The suspension was stirred at ambient temperature for $5 \mathrm{~min}$, benzoyl chloride $(155 \mathrm{mg}, 1.1 \mathrm{mmol})$ was added and stirring was continued for $1 \mathrm{~h}$. Chromatography on silica gel of the benzene soluble part of the reaction products yielded $75 \mathrm{mg}(36 \%)$ of $1 a$, m.p. $101-103{ }^{\circ} \mathrm{C}$ and $60 \mathrm{mg} \mathrm{(20 \% )} \mathrm{of} 3 b$, m.p. 
$120-123{ }^{\circ} \mathrm{C}$.

To a solution of $1 a(212 \mathrm{mg}, 1 \mathrm{mmol})$ in $4 \mathrm{ml}$ of pyridine was added acetic anhydride $(150 \mathrm{mg}, 1.5$ $\mathrm{mmol}$ ) and the solution was heated at $100-110^{\circ} \mathrm{C}$ for $39 \mathrm{~h}$. Benzene was added and the solvents were removed under reduced pressure. The residue was chromatographed on Florisil with chloroform as eluent and yielded $210 \mathrm{mg}(95 \%)$ of $1 a$, m.p. 97-99 ${ }^{\circ} \mathrm{C}$.

Reactions of $1 \mathrm{~b}$ with sodium hydride and acyl chlorides. A solution of $1 b(200 \mathrm{mg}, 1 \mathrm{mmol})$ in $25 \mathrm{ml}$ of tetrahydrofuran was treated with sodium hydride $(45 \mathrm{mg}, 1.1 \mathrm{mmol})$ for $40 \mathrm{~min}$ at $20^{\circ} \mathrm{C}$. Acetyl chloride $(160 \mathrm{mg}, 2 \mathrm{mmol}$ ) was added and the reaction mixture was stirred for $2 \mathrm{~h}$. Insoluble material was removed by filtration and the filtrate gave upon concentration and addition of diethyl ether $30 \mathrm{mg}(11 \%)$ of $4 d$, m.p. $162-163{ }^{\circ} \mathrm{C}$ dec. MS [m/e (\%, rel. int.)]: $240(1.2, \mathrm{M}-\mathrm{HCl})$. Mol. wt., obs. 240.0897 , calc. for $\mathrm{C}_{14} \mathrm{H}_{12} \mathrm{~N}_{2} \mathrm{O}_{2} 240.0899$. This product gave a positive Beilstein test for halogen. IR (nujol): $1740(\mathrm{~s}), 1640(\mathrm{~m}) \mathrm{cm}^{-1}$.

A solution of $1 b(200 \mathrm{mg}, 1 \mathrm{mmol})$ in $15 \mathrm{ml}$ of tetrahydrofuran was treated with sodium hydride (45 mg, $1.1 \mathrm{mmol}$ ) for $5 \mathrm{~min}$ at $20^{\circ} \mathrm{C}$. Benzoyl chloride $(140 \mathrm{mg}, 1 \mathrm{mmol})$ was added and the reaction mixture was stirred at $20{ }^{\circ} \mathrm{C}$ for $40 \mathrm{~min}$. The solvent was removed under reduced pressure and the residue was extracted with chloroform and water. The dried chloroform extract yielded $35 \mathrm{mg}$ $(10 \%)$ of $4 e, 155-157^{\circ} \mathrm{C}$ des. MS [m/e $(\%$, rel. int.)]: 302 (20.6, $\mathrm{M}-\mathrm{HCl}$ ). Mol. wt., obs. 302.1059, calc. for $\mathrm{C}_{19} \mathrm{H}_{14} \mathrm{~N}_{2} \mathrm{O}_{2} 302.1055$. This product gave a positive test for halogen. IR (nujol): 1745 (s), 1630 (m) $\mathrm{cm}^{-1}$.

Reaction of $1 \mathrm{c}$ with acetyl chloride. To a solution of $1 c(230 \mathrm{mg}, 1 \mathrm{mmol})$ in $10 \mathrm{ml}$ of acetonitrile was added acetyl chloride $(160 \mathrm{mg}, 2 \mathrm{mmol})$. The reaction mixture was heated at $70{ }^{\circ} \mathrm{C}$ for $0.5 \mathrm{~h}$. The precipitate was filtered, washed with acetonitrile and yielded $230 \mathrm{mg}(87 \%)$ of $1 c \cdot \mathrm{HCl}$, m.p. $190-193$ ${ }^{\circ} \mathrm{C}$ dec. IR (nujol): 1670 (s) $\mathrm{cm}^{-1}$.

Similar reactions of $1 a-1 e$ with acetyl chloride or benzoyl chloride yielded the hydrochlorides of the 2-pyridinecarboxanilides in 90-95\% yields.

Reactions of 1d with base and acyl chlorides. To a solution of $1 d(350 \mathrm{mg}, 1.5 \mathrm{mmol})$ in $4 \mathrm{ml}$ of pyridine was added benzoyl chloride $(210 \mathrm{mg}, 1.5$ $\mathrm{mmol}$ ) and the solution which turned purple was stirred at $20^{\circ} \mathrm{C}$ for $3.5 \mathrm{~h}$. Benzene was added and the solvents were removed under reduced pressure. The residue yielded $400 \mathrm{mg}$ of hygroscopic crystals upon addition of diethyl ether. This product was not further identified.

To a solution of $1 \mathrm{~d}(280 \mathrm{mg}, 1.2 \mathrm{mmol})$ in $10 \mathrm{ml}$ of benzene was added 2,4,6-trimethylpyridine $(240 \mathrm{mg}$, $2 \mathrm{mmol}$ ) and benzoyl chloride (170 $\mathrm{mg}, 1.2 \mathrm{mmol})$. The reaction mixture was stirred at ambient tem- perature for $90 \mathrm{~h}$ and the benzene-soluble part of the reaction mixture gave $200 \mathrm{mg}(71 \%)$ of $1 d$, m.p. $131-135{ }^{\circ} \mathrm{C}$ and $140 \mathrm{mg}$, m.p. $190-250{ }^{\circ} \mathrm{C}$ subl. which was not further identified.

A benzene solution of $1 d(150 \mathrm{mg}, 0.7 \mathrm{mmol})$, 2,4,6-trimethylpyridine $(85 \mathrm{mg}, 0.7 \mathrm{mmol})$ and 4biphenylcarbonyl chloride $(150 \mathrm{mg}, 0.7 \mathrm{mmol})$ was heated at $60{ }^{\circ} \mathrm{C}$ for $4 \mathrm{~h}$. The solid residue after removal of the benzene yielded $140 \mathrm{mg}(93 \%)$ of $1 d$, m.p. $135-137^{\circ} \mathrm{C}$ upon addition of acetonitrile.

A solution of $1 d(230 \mathrm{mg}, 1 \mathrm{mmol}) 2,4,6$-trimethylpyridine $(120 \mathrm{mg}, 1 \mathrm{mmol})$ and benzoyl chloride $(140 \mathrm{mg}, 1 \mathrm{mmol})$ in $5 \mathrm{ml}$ of nitromethane was heated at $80{ }^{\circ} \mathrm{C}$ for $2 \mathrm{~h}$. The benzene soluble part of the reaction mixture yielded $190 \mathrm{mg}(82 \%)$ of $1 d$, m.p. $130-135^{\circ} \mathrm{C}$.

A solution of equimolar amounts of $1 d, N, N$ dimethylaniline and benzoyl chloride in acetonitrile became dark. blue after heating for $5 \mathrm{~min}$ at $80^{\circ} \mathrm{C}$. The reaction products were not isolated.

Reactions of 2-pyridinecarbonyl chloride hydrochloride with triethylamine and acetanilide. To a suspension of 2-pyridinecarbonyl chloride hydrochloride (356 mg, $2 \mathrm{mmol}$ ) in $10 \mathrm{ml}$ of nitromethane was added triethylamine $(400 \mathrm{mg}, 4 \mathrm{mmol})$ and acetanilide $(270 \mathrm{mg}, 2 \mathrm{mmol})$. The black reaction mixture was stirred at $20^{\circ} \mathrm{C}$ for $100 \mathrm{~h}$. Chromatography on silica gel of the benzene soluble material yielded $100 \mathrm{mg}(37 \%)$ of acetanilide, m.p. 107$111{ }^{\circ} \mathrm{C}$ which was eluted with chloroform. No additional material was eluted with acetone from the column.

To a solution of acetanilide $(270 \mathrm{mg}, 2 \mathrm{mmol})$ in $10 \mathrm{ml}$ of benzene was added triethylamine (400 $\mathrm{mg}, 4 \mathrm{mmol}$ ) and 2-pyridinecarbonyl chloride hydrochloride ( $356 \mathrm{mg}, 2 \mathrm{mmol}$ ). The black solution was stirred for $21 \mathrm{~h}$ at $20^{\circ} \mathrm{C}$. The benzene soluble material yielded upon addition of diethyl ether $90 \mathrm{mg}$ $(33 \%)$ of acetanilide, m.p. $90-100{ }^{\circ} \mathrm{C}$ which also was identified by TLC.

Acknowledgement. Financial support from the Norwegian Research Council of Science and Humanities is gratefully acknowledged.

\section{REFERENCES}

1. Mørkved, E. H. Acta Chem. Scand. B 33 (1979) 433.

2. McCarty, C. G. and Garner, L. A. Rearrangements involving Imidic Acid Derivatives, In Patai, S., Ed., The Chemistry of Amidines and Imidates, Wiley, New York 1975, p. 221.

3. Mørkved, E. H. Acta Chem. Scand. B 33 (1979) 544. 
4. Kost, A. N. and Suminov, S. I. N-Acylpyridinium Salts, In Böhme, H. and Viehe, H. G., Eds., Iminium Salts in Organic Chemistry, Vol. 9; In Taylor, E. C., Ed., Advances in Organic Chemistry, Wiley, New York 1979, p. 608.

5. a. Curtin, D. Y. and Miller, L. L. J. Am. Chem. Soc. 89 (1967) 637; b. McKillop, A., Zelesko, M. J. and Taylor, E. C. Tetrahedron Lett. 48 (1968) 4945.

6. Hoy, D. J. and Poziomek, E. J. J. Org. Chem. 33 (1968) 4050.

7. Curtin, D. Y. and Miller, L. L. Tetrahedron Lett. $23(1965) 1869$.

8. Williams, D. H. and Fleming, I. Spectroscopic Methods in Organic Chemistry, 2nd Ed., McGraw-Hill, New York 1973, p. 47.

9. Moon, M. W., Bell, L. T. and Webster, D. M. J. Org. Chem. 39 (1974) 315.

10. Mørkved, E. H. and Cronyn, M. W. Acta Chem. Scand. B 32 (1978) 231.

11. Mirek, J. Zesz. Nauk. Uniw. Jagiellon., Pr. Chem. 10 (1965) 61; Chem. Abstr. 66 (1967) $37125 \mathrm{~h}$.

12. Rappoport, Z. and Ta-Shma, R. J. Am. Chem. Soc. 99 (1977) 1845.

13. Ugi, I., Beck, F. and Fetzer, U. Chem. Ber. 95 (1962) 126.

Received December 7, 1979. 